\title{
Overcome Compassion Fatigue and Burnout
}

\author{
Linda Sage MA, BA Ed (Hons) \\ Successful Mindset Ltd, UK
}

*Corresponding author

Linda Sage MA, BA Ed (Hons), Successful Mindset Ltd, UK, Tel: +44 07908529 521; E-Mail: info@lindasagementoring.com. www. lindasage.com.

Submitted: 08 May 2017; Accepted: 11 May 2017; Published: 13 May 2017
As another exhausting shift comes to an end with an aching back, feet and legs, your body screaming for the rest it needs, but your mind is in overdrive and thinking about what awaits you at home. The daily duties and responsibilities build up over time to become huge burdens that seem to weigh you down and keep you pinned to where you are now, without much possibility of change on the horizon. The feeling of being overwhelmed and in a constant battle with life, just to keep up. Then to top it all, when you can finally slump into your bed, sleep is elusive, or minimal, thus making the next day start off with negatives.

The medical field globally is in a staffing crises, losing more experienced staff than is being replaced by new recruits, putting even more pressure on the staff that are left working. Long hours, emotional, psychological and physical stress, along with demands of professional excellence, and mounting paperwork are an everyday scenario in the medical world. So, unfortunately, it is not surprising that medical practitioners are not only the No1. Professionals for burning out [1], but also for suicide rates as well [2]. The caring professionals all seem to care for themselves last. Their sense of duty and loyalty are extreme, but somewhere there needs to be some balance, both mentally and physically.

The words, "that's just how it is'," "Oh, I am ok really," "its nothing, I will be fine tomorrow," and the list goes on! These self-effacing statements, devalue yourself, your needs and your entitlement to equality of care. It is true that doctors and nurses make the worse patients, because they want to be up and back to it, in as fast a time as possible. Until one day, the time bomb explodes and you are either knocked off your feet (sometimes literally) by an emotional, psychological, of physical illness, that will take a major amount of time to cure. No medical professional is super human, though each and everyone by nature, feels to need to be Superman or Wonder woman on a daily basis. Even they were not saving the world all day, everyday, they had their alter egos and down time.

Dealing on a daily basis with traumatic and emotionally challenging people and situations, takes a lot of energy, and dealing with heart wrenching scenarios is extremely hard. Very often medical staff take on responsibility for outcomes and happenings far out of their own control, but for the majority they are morally accountable in their own mind for the failings of others. Very often making excuses for others, only to condemn themselves harshly.

Learning to let go, being prepared to relinquish the reins of not only your life, but of those around you is a huge step forward. You personally cannot, police and fix every vulnerable soul, or injured body in the world; though usually you would like to try. Believing in the ability of others, promoting empowerment of individuals helps you to reduce your work load and open up your time.

Compassion fatigue runs at over $70 \%$ of health/medical workers, saying that they have felt anxious or overwhelmed in their current position, the age group as well makes a difference under 40 means you are in the highest bracket of leaving your profession, or at least changing careers. The good news is, if you make it to 55, your likelihood is reduced considerably to just over $30 \%$, but that is still high compared to other professions, even police, dentists and teachers.

97\% of all HR Directors in a recent poll, have stated that staff wellbeing is an important factor of a successful business, but they also say that less than $70 \%(67 \%)$ have any wellbeing staff benefits, and again those that actively encourage staff wellbeing is down to $32 \%$. It is painfully clear, that considerable action needs to be taken in this area. Part of the JCI and quality standards are staff wellbeing, so not only does your employer have a responsibility for your care and well being, you do too. It is also true, that when employers provide wellbeing offers, not all staff take advantage of them.

Patient and critical care suffer when staff are not rested and refuled for their next shift, the decline in care and increase in mistakes are assured, thus opening the door for costly negligence suits, patience complaints and staff disciplinary actions.

Being self aware, is not a luxury in your profession it is a necessity, taking time out, learning meditation, or stress busting techniques is not a waste of time, money or effort. Your body and mind have limits, know what yours are and support them. Challenging yourself is not the problem, for the most; that is a to do and certainly as humans, we grow personally and professionally through adversity and tough times, but to keep yourself permanently in this tension, sooner or later something will snap. Prevention is a thousand times better than any cure.

Most practitioners do not know they are suffering with Compassion Fatigue until they are overwhelmed or burnt out. Learn the symptoms, recognize changes in yourself, and ask for help. For many self-prescribing is a slippery, downward slide, find a colleague you can trust, one you can talk to and open up; this is not a sign of weakness, it is a sign of strength. Also, if you are in a 
supervisory position, be aware of your team, their circumstances, and their needs. Being involved, valued and acknowledged, by line managers, and senior staff keeps each individual in every team in sync with employment strategies. Providing better outcomes for the staff, patients and the business bottom line [3].

Mood swings, reduced productivity, arguing with management and colleagues or resistant to changes in routines, along with increased absenteeism are all easily recognizable patterns, designate a buddy system to help staff support each other, offer venting places, allowing staff to let off steam and rage for a minute, reduces long term stress building up.

Logically as medically qualified individuals, you know the high risks that stress carries; blood pressure, strokes, heart attacks, emotional eating leading to body mass issues, joint and bone fractures, along with knock on effects such as muscle, ligaments, eye strain, lack of vitamins and minerals to balance the body, in reality the list is endless. All in all, time given to relaxation, hydration, and general wellbeing, mean a long term benefit for the individual, the patients and the establishment.

Taking the time to be the best professional you can be, the best supervisor, the best manager will set the standard for those around you. Lead by example, lead by empowerment, there is never a perfect time to start this as every day is a busy one, but the sooner you make a change, the sooner your wellbeing and life will change; then in turn so will the life of others.

\section{References}

1. http://mentalhealthdaily.com/2015/01/06/top-11-professionswith-highest-suicide-rates/

2. http://stress.lovetoknow.com/Which_Professionals_are_ Prone to Burnout

3. http://www2.cipd.co.uk/pm/peoplemanagement/b/weblog/ $\operatorname{archive} / 2017 / 03 / 03 /$ what-s-the-future-of-employeewellbeing.aspx
Copyright: @2017 Linda Sage. This is an open-access article distributed under the terms of the Creative Commons Attribution License, which permits unrestricted use, distribution, and reproduction in any medium, provided the original author and source are credited. 